\title{
Phenobarbitone Induced Toxic Epidermal Necrosis in a Young Patient - A Rare Clinical Presentation: A Case Report and Brief Review of the Literatures
}

Biniyam A. Ayele ( $\sim$ biniyam.a7@gmail.com )

Addis Ababa University School of Medicine https://orcid.org/0000-0002-7955-6030

Kemal Ali

Addis Ababa University Faculty of Medicine: Addis Ababa University School of Medicine

Eliyas Mulatu

Addis Ababa University Faculty of Medicine: Addis Ababa University School of Medicine

\section{Case report}

Keywords: Phenobarbitone, Toxic epidermal necrosis, asthma, hypersensitivity, Ethiopia

Posted Date: April 27th, 2021

DOI: https://doi.org/10.21203/rs.3.rs-458796/v1

License: @ (i) This work is licensed under a Creative Commons Attribution 4.0 International License. Read Full License 


\section{Abstract}

Background: Toxic epidermal necrolysis (TEN)/ Stevens-Johnson syndrome (SJS) is the spectrum of severe, acute, mucocutaneous, Ig E mediated hypersensitivity reaction; universally related to different drugs.

Phenobarbitone is known to cause hypersensitivity reactions with benign pattern; ranging from a mild to moderate rashes but not life-threatening reactions such as TEN/SJS. Little is known about TEN in asthmatic patient. To the best of our knowledge, this is the first case of Phenobarbitone-induced TEN in a young asthmatic patient from the sub Saharan African.

Case report: We report a 14-year-old right handed asthmatic male patient who presented with extensive blister skin eruptions involving the whole body including mouth ear canal later followed by skin exfoliation associated with low grade fever, sore throat, and dysphagia. The hypersensitivity skin reaction developed two weeks after initiation of Phenobarbitone of 100mg twice daily for a new onset generalized tonic clonic seizure. The exfoliation also involved oral and Conjunctival mucosa; with estimated $65 \%$ body surface area involvement; hence the diagnosis of Toxic epidermal necrosis was made. The Laboratory investigations were relevant for mild leucocytosis, prolonged prothrombin time, and reduced albumin. Phenobarbitone was discontinued and replaced with clonazepam; and the patient was managed with fluids replacement, IV antibiotics, twice daily wound care, analgesics, and naso gastric tube feeding. On subsequent days in intensive care unit (ICU), the patients' clinical condition started improving; the skin lesion also started to heal and exfoliate in most of the affected skin surface areas, and the patient was discharges improved after ten days of ICU care.

Conclusion: In summary, the present case describes, a 14-years-old young child with history of allergy in a form of asthma and new onset seizure disorder; and developed toxic epidermal necrosis following exposure to Phenobarbitone. This case also highlighted the benign prognosis observed in paediatrics population with TEN.

\section{Background}

Toxic epidermal necrolysis (TEN)/ Stevens-Johnson syndrome (SJS) is the spectrum of severe, acute, mucocutaneous, Ig E mediated hypersensitivity reaction; universally related to different drugs; which typically appears 1-3 weeks after the beginning of therapy. More than 100 medications have been implicated in this syndrome (1-4). The incidence of TEN is 2 cases per million persons per year (5). Phenobarbitone is known to cause hypersensitivity reactions with benign pattern; ranging from a mild to moderate rashes but not lifethreatening reactions such as TEN/SJS. TEN is considerable associated with high morbidity and mortality; it is an exfoliative disease and results in full-thickness damage to the epidermis, characterized by a widespread bullae formation with epidermal necrosis and idiosyncratic of the skin and mucous membranes. TEN mainly occurs in adults and is often attributable to drug sensitivity and considered to be a severe form of StevensJohnson syndrome (SJS) $(1,3,5-8)$. To the best of our knowledge, this is the first case of Phenobarbitoneinduced toxic epidermal necrosis in a young adolescent patient from the sub Saharan African (SSA) region.

\section{Case Report}

We report a 14-year-old right handed male patient with known history of asthma, cardiomyopathy, and secondary erythrocytosis; who presented with extensive blister skin eruptions involving the whole body including mouth ear 
canal later followed by skin exfoliation associated with low grade fever, sore throat, and dysphagia. Three weeks prior to his current presentation, he was admitted to a local hospital for heart failure and pneumonia and treated accordingly. After six days of admission, the patient developed three episodes of generalized tonic clonic seizure each lasted few minutes; for which he was started on phenobarbital 100mg twice daily and discharged home with improvement. Up on presentation, blood pressure was 100/60 mmHg; pulse rate 100 beat per minutes; respiratory rate was 20 ; temperature $38.3^{\circ} \mathrm{C}$; and oxygen saturation was $94 \%$ on atmospheric air. Oral examination shows, lesions involving his oral cavity and both lips. Ruptured blisters and extensive skin exfoliation all over the body involving approximately $65 \%$ of total body surface area (Fig. 1a \& 1b). Laboratory investigations were unremarkable, except mild leucocytosis, prolonged prothrombin time, and reduced albumin; the rest of the laboratory investigations were summarized in the table below (Table 1). Echocardiography (ECHO) shows dilated right ventricle and right atrium with right ventricular hypertrophy. Brain computer tomography (CT) shows hyperdense cerebral vessels likely due to Polycythemia Vera. The patient was admitted to medical intensive care unit (ICU) with consideration of Phenobarbitone induced Toxic epidermal necrosis, as the surface area affected by the exfoliating skin lesion was 65\%; which fulfilled the criteria to diagnose TEN. Thus, Phenobarbitone was immediately discontinued and replaced with clonazepam; and in addition the patient was managed with fluids replacement, IV antibiotics, twice daily wound care, analgesics, and naso gastric tube feeding. On subsequent days in ICU, the patients' clinical condition started improving; the skin lesion also started to heal and exfoliate in most of the affected skin surface areas. After 10 days of ICU management the patient was discharged home improvement and follow up appointment. 
Table 1

List of patient's laboratory investigations with normal reference value

\begin{tabular}{|c|c|c|}
\hline & & Normal reference values \\
\hline White blood cells (WBC) & 13, 400 (N 76\%, L 11.8\%) & $5000-11,000$ cells $/ \mathrm{mL}$ \\
\hline Hemoglobin (Hgb) & $14.4 \mathrm{~g} / \mathrm{dL}$ & $14-16 \mathrm{~g} / \mathrm{dL}$ \\
\hline Mean corpuscular volume (MCV) & $83.1 \mathrm{fL}$ & $80-99 \mathrm{fL}$ \\
\hline Platelets & 302,000 cells $/ \mathrm{mL}$ & $150,000-350,000$ cells $/ \mathrm{mL}$ \\
\hline Creatinine & $0.2 \mathrm{mg} / \mathrm{dL}$ & $0.5-1.2 \mathrm{mg} / \mathrm{dL}$ \\
\hline Blood urea nitrogen & $11 \mathrm{mg} / \mathrm{dL}$ & $5-18 \mathrm{mg} / \mathrm{dL}$ \\
\hline ALT & $16 \mathrm{IU} / \mathrm{L}$ & $10-59 \mathrm{U} / \mathrm{L}$ \\
\hline AST & $10 \mathrm{IU} / \mathrm{L}$ & $10-40 \mathrm{U} / \mathrm{L}$ \\
\hline Alkaline phosphatase & $70 \mathrm{IU} / \mathrm{L}$ & $20-140 \mathrm{U} / \mathrm{L}$ \\
\hline Sodium & $137 \mathrm{mmol} / \mathrm{L}$ & $135-146 \mathrm{mmol} / \mathrm{L}$ \\
\hline Potassium & $3.3 \mathrm{mmol} / \mathrm{L}$ & $3.5-4.5 \mathrm{mmol} / \mathrm{L}$ \\
\hline Chloride & $97 \mathrm{mmol} / \mathrm{L}$ & 96-106 mmol/L \\
\hline Prothrombin time (PT) & $18.1 \mathrm{sec}$ & $12.0-14.0 \mathrm{sec}$ \\
\hline Partial thromboplastin time (PTT) & $41.6 \mathrm{sec}$ & $20-35 \mathrm{sec}$ \\
\hline INR & 1.52 & \\
\hline Total bilirubin & $0.4 \mathrm{mg} / \mathrm{dL}$ & $0.2-1.3 \mathrm{mg} / \mathrm{dL}$ \\
\hline Direct bilirubin & $0.08 \mathrm{mg} / \mathrm{dL}$ & $0.0-0.3 \mathrm{mg} / \mathrm{dL}$ \\
\hline Albumin & $2.2 \mathrm{~g} / \mathrm{dL}$ & $3.5-5.0 \mathrm{~g} / \mathrm{dL}$ \\
\hline HIV serology & Negative & \\
\hline
\end{tabular}

\section{Discussion And Conclusion}

The present case, describes a child who presented with clinical features suggestive of TEN with large surface area affection after exposed to Phenobarbitone. The case also highlights the good prognosis observed in young patients with TEN. The present case has comorbid asthma, which is allergy-induced airway reactivity; likely predisposing the patient to hypersensitivity reaction such as TEN. This is consistent with previous reports indicating risk factors of TEN/SJS including, history of allergy, advanced age, epilepsy, HIV infection, pre-existing liver disease, and chronic underlying diseases $(9,10)$. The risk factors identified in the present case were history of allergy (asthma) and history of seizure. Thus, it's important to follow a cautious approach when prescribing commonly known medications associated with TEN/ or SJS in patients having risk factors of TEN/ or SJS. The present case describes a case of TEN in a young boy. However, previous studies shows low prevalence of Toxic 
epidermal necrosis in paediatrics age group; furthermore, mortality rates in children with TEN are lower ranging from 0 to $7.5 \%$ compared to an overall mortality in adults which is approximately $30 \%(1,8-11)$. Therefore, it's vital to have high index of suspicion towards this severe adverse drug reactions characterized by a low incidence but high mortality, even in a young children.

Toxic epidermal necrosis is associated with drug exposure in up to $90 \%$ of the cases. These drugs includes: anticonvulsants, antibiotics, allopurinol, and non-steroidal anti-inflammatory $(3,4,7,12-14)$. In the present case, the child was started on Phenobarbitone, one of the common culprit drug associated with TEN $(11,14)$. Likewise, other antiepileptic drugs (AED) were also incriminated with this deadly hypersensitivity skin reaction; few of these AEDs include: phenytoin, carbamazepine, Oxcarbazepine, and Lamotrigine $(4,12,15,16)$. Therefore, clinicians should be aware of these drugs which are highly associated with TEN and should replace with drugs associated with lower skin hypersensitivity reactions. Skin and liver are the most affected organs by $\operatorname{TEN}(9,10)$. However, the present case had no clinical sign of liver injury, but had mild biochemical derangement suggestive of liver damage in the form of mild prolongation of prothrombin and partial thromboplastin time (Table 1). This finding further indicates the benign prognosis of TEN in pediatrics population.

Toxic epidermal necrosis is a multi-organ disease that not only affects the skin and mucous membranes but also several internal organs. Therefore, a multi-disciplinary approach is required. In a first step, immediate withdrawal of potentially causative drugs, ideally in the early stages of the disease, is mandatory to reduce fatality in SJS/TEN; in addition, supportive cares such as: fluid replacement, would care, and nutritional support is commended $(1,5,8,9,11)$. In the present case, the identified offending drug was Phenobarbitone, which we immediately discontinued. In addition, the child was given fluid replacement, intravenous antibiotics, and daily wound care; and discharged home improved.

In summary, the present case describes, a 14-years-old young child with history of allergy in a form of asthma and new onset seizure disorder; and developed toxic epidermal necrosis following exposure to Phenobarbitone. This case also highlighted the benign prognosis observed in pediatrics population with TEN.

\section{Declarations}

\section{Ethics approval and consent to participate:}

The authors' institution does not require ethical approval for the publication of a single case report.

\section{Consent to publication:}

Written informed consent was obtained from the patient family for publication of this case report and any accompanying images. A copy of the written consent is available for review by the Editor-in-Chief of this journal.

\section{Availability of data and materials:}

All data sets on which the conclusions of the case report based, to be available as a medical record document and available from the corresponding author on reasonable request from the editors.

\section{Funding:}


None

\section{Competing interests:}

The authors declare that they have no competing interests.

\section{Authors' contributions:}

$\mathrm{BAA}, \mathrm{KA}$, and EM were involved in concept design for the manuscript, manuscript preparation, critical analysis, and revision; and involved in the management of the patient.

\section{Acknowledgements}

We would like to acknowledge the patient's and his family for their support. We also would like to acknowledge all the nursing staff, treating physicians and supporting staff involved in the management of our patient.

\section{References}

1. Nurtdinova G, Galimova E, Zagidullin N, Kucher O. 10-years register of Stevens-Johnson syndrome and toxic epidermal necrosis analysis. World Allergy Organ J [Internet]. 2020;13(8):100256. Available from: https://doi.org/10.1016/j.waojou.2020.100256

2. Rahimi EA, Ghanei Gheshlagh R, Dehvan F. Toxic epidermal necrosis syndrome after taking nonsteroidal antiinflammatory drugs: a case report. Sci J Nursing, Midwifery Paramed Fac. 2018;3(4):77-82.

3. Elazzazy S, Abu Hassan T, El Seid A, Jacob CM. Toxic Epidermal Necrolysis Associated with Antiepileptic Drugs and Cranial Radiation Therapy. Case Rep Oncol Med. 2013;2013(August 2012):1-3.

4. Barkakaty S, K. G. Phenytoin induced toxic epidermal necrolysis: a case report. Int J Basic Clin Pharmacol. 2019;8(6):1448.

5. Gubinelli E, Canzona F, Tonanzi T, Raskovic D, Didona B. Toxic epidermal necrolysis successfully treated with etanercept. J Dermatol. 2009;36(3):150-3.

6. AlQuliti K, Ratrout B, AlZaki A. Antiepileptic drugs toxicity: A case of toxic epidermal necrolysis in patient with phenytoin prophylaxis post-cranial radiation for brain metastases. Saudi Pharm J [Internet]. 2014;22(4):381-4. Available from: http://dx.doi.org/10.1016/j.jsps.2014.02.001

7. Saiag P, Caumes E, Chosidow O, Revuz J, Roujeau JC. Drug-induced toxic epidermal necrolysis (Lyell syndrome) in patients infected with the human immunodeficiency virus. J Am Acad Dermatol [Internet]. 1992;26(4):567-74. Available from: http://dx.doi.org/10.1016/0190-9622(92)70082-Q

8. French LE. Toxic epidermal necrolysis and Stevens Johnson syndrome: Our current understanding. Allergol Int [Internet]. 2006;55(1):9-16. Available from: http://dx.doi.org/10.2332/allergolint.55.9

9. Lerch M, Mainetti C, Terziroli Beretta-Piccoli B, Harr T. Current Perspectives on Stevens-Johnson Syndrome and Toxic Epidermal Necrolysis. Clin Rev Allergy Immunol. 2018;54(1):147-76.

10. Manchanda Y, Das S, Sarda A, Biswas P. Controversies in the Management of Cutaneous Adverse Drug Reactions Systemic Corticosteroids in the Management of SJS / TEN : Is it Still. Indian J Dermatol [Internet]. 2018;63(2):125-30. Available from: https://www.scopus.com/inward/record.uri?eid=2-s2.085045467996\&doi=10.4103\%2Fijd.IJD_585_17\&partnerID=40\&md5=24ac1ecf391acb36c5e83a65633c1c90 
11. R. Zankat DD, J. Sheth DH, G. Chaudhary DR, D. Malhotra DS, R. Patel DP. A case report on phenobarbitone induced stevens-johnson syndrome: an alarming hypersensitivity reaction. Int J Med Res Rev. 2018;6(3):200-3.

12. Maitra A, Bhattacharyya S, Mukherjee S, Era N. A rare case of oxcarbazepine induced Stevens Johnson Syndrome: toxic epidermal necrosis overlap. Int J Basic Clin Pharmacol. 2017;6(2):466.

13. Stern RS, Divito SJ. Stevens-Johnson Syndrome and Toxic Epidermal Necrolysis: Associations, Outcomes, and Pathobiology-Thirty Years of Progress but Still Much to Be Done. J Invest Dermatol [Internet]. 2017;137(5):1004-8. Available from: http://dx.doi.org/10.1016/j.jid.2017.01.003

14. Gaur S, Agnihotri R. Phenobarbital induced Stevens-Johnson syndrome in a child. Indian J Pharmacol. 2012;44(4):531-2.

15. Varghese SP, Haith LR, Patton M Lou, Guilday RE, Ackerman BH. Lamotrigine-induced toxic epidermal necrolysis in three patients treated for bipolar disorder. Pharmacotherapy. 2006;26(5 I):699-704.

16. LIU J, LU S-C, LIU J-L, YANG H-M. t Toxic epidermal necrosis induced by carbamazepine. 2018;93(4):620-1.

\section{Figures}

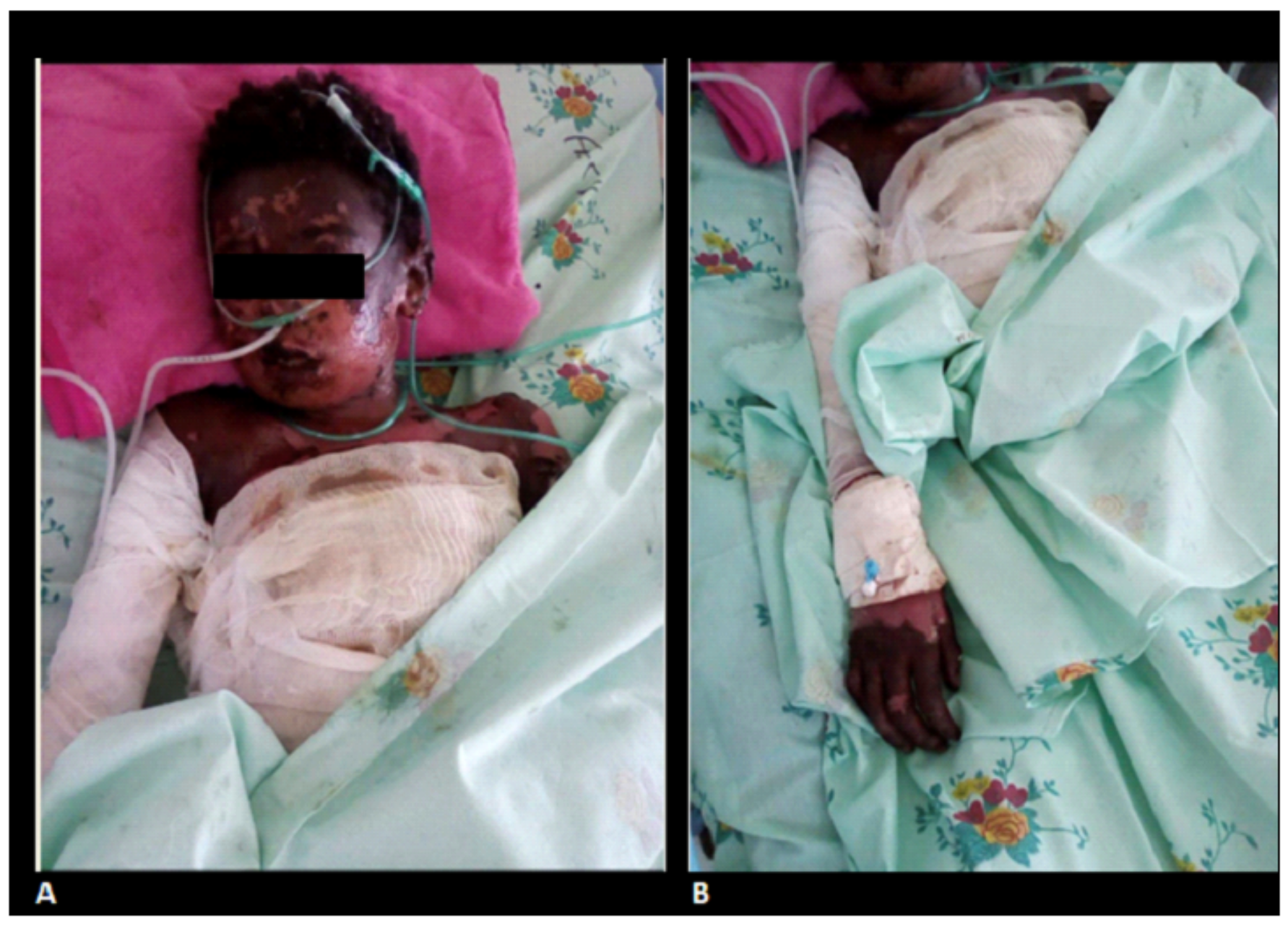

Figure 1 
(a) Showing ruptured blisters and extensive skin exfoliation involving face, oral cavity, chest, abdominal region (dressed) and limbs (65\% of total body surface area) 